\title{
Model Ontologi untuk Penjadwalan Kuliah di Program Studi Teknik Informatika Fakultas Teknik Universitas Muria Kudus
}

\author{
Mukhamad Nurkamid' ${ }^{1}$, Ahmad Jazuli ${ }^{2}$, Dimas Adi Nugroho ${ }^{3}$, Rizal Abdullah Mahfud ${ }^{4}$ \\ ${ }^{1}$ Program Studi Teknik Informatika, Fakultas Teknik Universitas Muria Kudus \\ Gondangmanis PO BOX 53 Bae Kudus 59327, 0291-438229, e-mail: \\ muhammad.nurkamid@umk.ac.id \\ 2Program Studi Teknik Informatika, Fakultas Teknik Universitas Muria Kudus \\ Gondangmanis PO BOX 53 Bae Kudus 59327, 0291-438229, e-mail:ahmad.jazuli@umk.ac.id \\ ${ }^{3}$ Program Studi Teknik Informatika, Fakultas Teknik Universitas Muria Kudus \\ Gondangmanis PO BOX 53 Bae Kudus 59327, 0291-438229, e-mail:dimasnugroho2709@gmail.com \\ ${ }^{4}$ Program Studi Teknik Informatika, Fakultas Teknik Universitas Muria Kudus \\ Gondangmanis PO BOX 53 Bae Kudus 59327, 0291-438229, e-mail:rizalmahfud125@gmail.com
}

\section{ARTICLE INFO}

Article history:

Received 15 June 2021

Received in revised form 20 July 2021

Accepted 26 July 2021

Available online 31 July 2021

\begin{abstract}
The purpose of this study is to build a data model for scheduling lectures at the Informatics Engineering Study Program, Faculty of Engineering, Muria Kudus University uses ontology as part of the implementation of semantic web technology. System built based on existing schedule data in the Informatics Engineering Study Program, such as data days, courses, credits, space and time stored in RDF / OWL format. The use of a lot of data with different storage formats becomes problems in finding valid information. To overcome this, it is necessary a system that can provide complete information is needed, namely with using semantic web technology. The semantic web is used to understand meaning of a word and concept, because it builds interconnected resources. Semantic web implementation is built using the ontology approach applied to RDF/OWL format. The results of this study are improving the ability of computers to search for more informationrich lecture schedules in the Informatics Engineering Study Program.
\end{abstract}

Keywords: ontology, schedule, RDF/OWL.

\section{Pendahuluan}

Ketersedian informasi yang mudah dan murah menjadi kebutuhan setiap orang era teknologi internet. Internet memberikan banyak manfaat bagi setiap orang yang mengakses. Selain memberikan kemudahan-kemudahan, internet menghadirkan banyak pilihan media akses yang diberikan kepada penggunanya, yaitu menggunakan banyak perangkat (platform) yang bisa saling berkolaborasi seperti melalui web dan mobile. Internet saat ini telah menjadi salah satu kebutuhan utama bagi penggunanya, terutama untuk bertukar informasi serta mendapatkan informasi terbaru secara cepat, mudah dan murah [1].

Sumber daya web (web resource) adalah sumber informasi yang terdapat dalam web (internet) seperti yang menampilkan berbagai ragam informasi mengenai berita, hiburan, ebook, digital library dan newspaper dengan URI (Uniform Resource Identifier) sebagai pengidentifikasi unik yang menjadi pembeda antar resource. Permasalahan yang selanjutnya 
timbul adalah ketika sumber daya web yang besar dan beragam tersebut tersimpan secara tersebar dengan format yang belum standar, bebas dan tidak terstruktur, sehingga berdampak kepada pengguna dalam pencarian data/ informasi yang dibutuhkan [2]. Dari berbagai permasalahan tersebut, diperlukan teknik penyimpanan data yang efektif yaitu dengan menggunakan ontologi (ontology), dimana ontologi sebagai database yang akan menyimpan seluruh data-data yang telah dikelompokkan kedalam sturktur hirarki class.

Ontologi merupakan alternatif cara menyimpan sebuah data dari sekumpulan konsepkonsep dalam sebuah domain informasi dan menghubungkan data tersebut satu sama lain (relationships). Ontologi dapat digunakan untuk menyajikan informasi secara semantik dan melakukan pengorganisasian data, pemetaan, sehingga sumber daya informasi dapat dimodelkan secara sistematis dan terstruktur. Dengan model penyimpanan data dengan ontologi, interoperabilitas data lebih terjaga karena data-data yang disimpan dapat dilakukan integrase dan manipulasi dengan lebih efektif dan efisien [3]. Noy dan McGuinnes mendefinisikan bahwa ontologi adalah sebuah deskripsi formal yang eksplisit dari konsep dalam sebuah domain yang terdiri dari classes (kadang disebut sebagai konsep), properti dari masing-masing konsep yang mendeskripsikan berbagai fitur dan atribut dari konsep disebut slot (juga disebut sebagai roles atau properti), dan pembatasan pada slot yang disebut facets (role restrictions)[4].

Penggunaan ontologi untuk membangun sistem berbasis teknologi web semantik telah banyak dilakukan beberapa peneliti sebelumnya. Misalnya, ontologi untuk sistem Koleksi Laporan Skripsi dan PKL[5], Bibliografi Perpustakaan [6], Sistem Pencarian Dosen Pembimbing Skripsi [7], Sistem Pencarian Obat [8], Pencarian Program Studi [9] dan ontologi yang digunakan untuk Informasi Pariwisata [10].

Dengan ontologi sebagai media penyimpanan datanya, pencarian informasi dapat sesuai keinginan pengguna karena data memiliki hubungan melalui sebuah pernyataan triple, yang terdiri subyek, predikat dan objek dalam hal ini diterapkan penggunaan Resource Description Framework $(R D F)$. Ontologi memungkinkan dokumen dapat diproses dan dicari sesuai kriteria yang diberikan[11]. Program studi Teknik informatika dalam pembuatan jadwal kuliah telah memanfaatkan sistem akademik yang ada. Namun persoalan yang muncul dalam sistem akademik tersebut sistem pencariannya masih menggunakan pendekatan kriteria. Dengan pendekatan kriteria, jika data jadwal yang ada di program studi banyak maka hasil pencarian sulit ditemukan, sehingga pencarian jadwal tidak sesuai harapkan pengguna.

Tujuan penelitian ini adalah mengembangkan model ontologi pada domain akademik yang diterapkan pada sistem penjadwalan kuliah di Program Studi Teknik Informatika Fakultas Teknik Universitas Muria Kudus. Kemudian melakukan pengujian terhadap model ontologi melalui pertanyaan-pertanyaan yang sering ditanyakan pengguna dalam mengakses informasi jadwal kuliah dengan queri SPARQL.

\section{Metode Penelitian}

Tahapan penelitian yang digunakan pada penelitian ini adalah:

a. Menetukan daftar istilah yang akan di bangun dalam koleksi sistem penjadwalan kuliah pada program studi.

b. Mendefinisikan class dan menyusun hirarki class.

c. Merancang ontologi untuk sistem penjadwalan kuliah.

d. Mendefinisikan properti class. 
e. Mendefinisikan facet (batasan) dari properti. Didalam pengembangan ontologi, facet property didefinisikan menjadi dua kategori, yaitu cardinality, yang mendefinisikan banyaknya nilai dari setiap properti. Kemudian yang kedua adalah type, yang menegaskan tipe data pada properti yang digunakan pada ontologi.

f. Menguji ontologi dengan queri SPARQL untuk menjawab pertanyaan-pertanyaan seputar jadwal kuliah.

Adapun alat dan bahan yang digunakan adalah:

a. Data jadwal Program Studi Teknik Informatika Semester Gasal 2020/2021.

b. Tools ontologi dengan Protégé.

c. Laptop/ PC.

\section{Hasil Pembahasan}

\subsection{Perancangan Ontologi}

Tahapan pertama di dalam penelitian ini adalah mengimplementasikan ontologi didasarkan pada perancangan ontologi yang telah dibuat. Implementasi ontologi dilakukan dengan membuat class, object property dan data property pada aplikasi Protege dalam format owl. Hasil perancangana ontologi ini disimpan dengan nama kuliah. owl dapat dilihat pada tabel 1 dan tabel 2 .

Tabel 1. Class, Sub Class dan Object Property.

\begin{tabular}{lll}
\hline Class & Sub Class & Object Property \\
\hline CivitasAkademika & Thing & \\
Jadwal & Thing & \\
Dosen & CivitasAkademika & teachBy \\
Kelas & Jadwal & hasClass \\
Matakuliah & Jadwal & \\
Ruangan & Jadwal & hasRoom \\
Semester & Jadwal & hasSemester \\
SKS & Jadwal & \\
Waktu & Jadwal & hasTime \\
Periode & Thing & hasPeriod \\
TahunAkademik & Thing & hasYear \\
\hline
\end{tabular}

Tabel 2. Data Property, Domain dan Range

\begin{tabular}{lll}
\hline Data Property & Domain & Range \\
\hline academic_year & Tahun_Akademik & String \\
class_name & Kelas & string \\
course_name & Matakuliah & string \\
day & Waktu & string \\
dosen_name & Dosen & string \\
nidn & Dosen & integer \\
period & Matakuliah & string \\
room_name & Ruangan & string \\
room_capacity & Ruangan & integer \\
semester & Semester & string \\
sks & SKS & integer \\
\hline
\end{tabular}




\subsection{Implementasi Ontologi}

Setelah dilakukan perancangan ontologi pada tahap 3.1, langkah selanjutnya adalah implementasi konsep ontologi meggunakan Protege. Pada tahapan ini, dibuat class dan subclass yang merepresentasikan koleksi semua dokumen yang dilengkapi dengan informasi dan disusun berdasar suatu klasifikasi dan dikelompokkan kedala jenis-jenis yang sama.

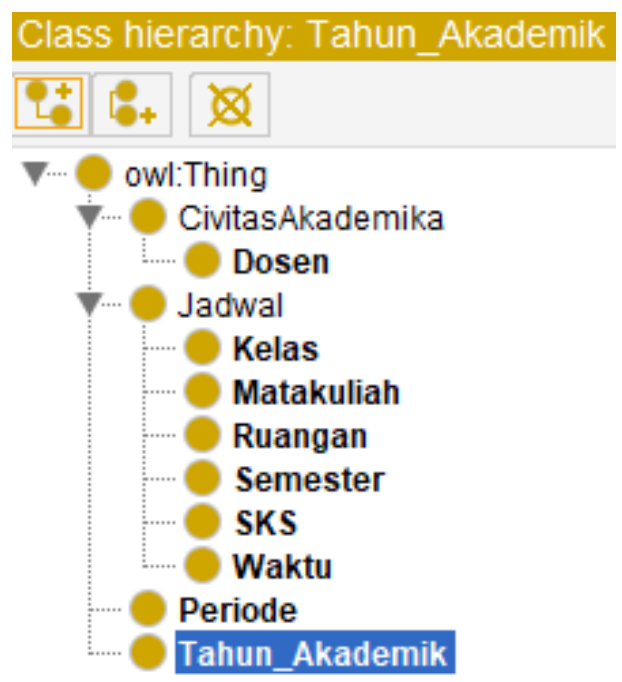

Gambar 1. Struktur Hirarki Sistem Penjadwalan Kuliah

Gambar 1 merupakan implementasi class dari domain akademik pembuatan jadwal kuliah. Thing merupakan root class. Object property dari ontologi domain sistem penjadwalan dapat klasifikasikan menjadi beberapa istilah seperti hasClass, hasPeriode, hasRoom, hasSemester, hasSKS, hasTime, hasYear, dan teachBy. Lebih lengkapnya dapat dilihat pada gambar 2 .

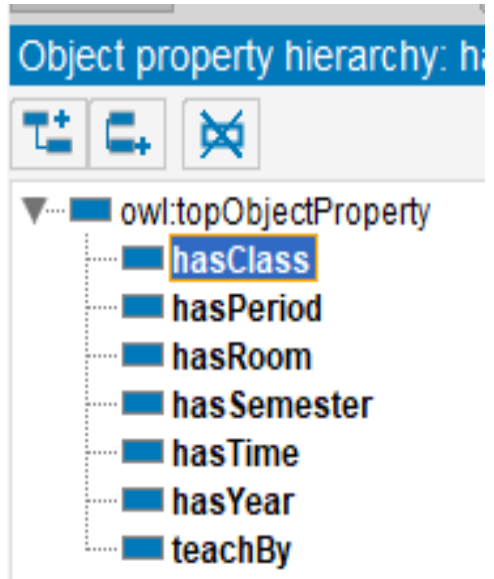

Gambar 2. Penggunaan Object perperty dalam Sistem Penjadwalan

Gambar 2 merupakan implementasi object property yang menghubungkan antara objek-objek (class) pada desian ontologi sistem penjadwalan kuliah. Pada Gambar 2 dapat dijelaskan bahwa object property "teachBy" menghubungkan objek "Matakuliah" dengan objek "Dosen". Yang artinya, setiap matakuliah diampu oleh beberapa dosen. Sedangkan pada gambar 3 merupakan implementasi dari data property yang dimiliki oleh 
setiap objek (class), misal objek Matakuliah memiliki beberapa data property course_id, course_name dan sks.

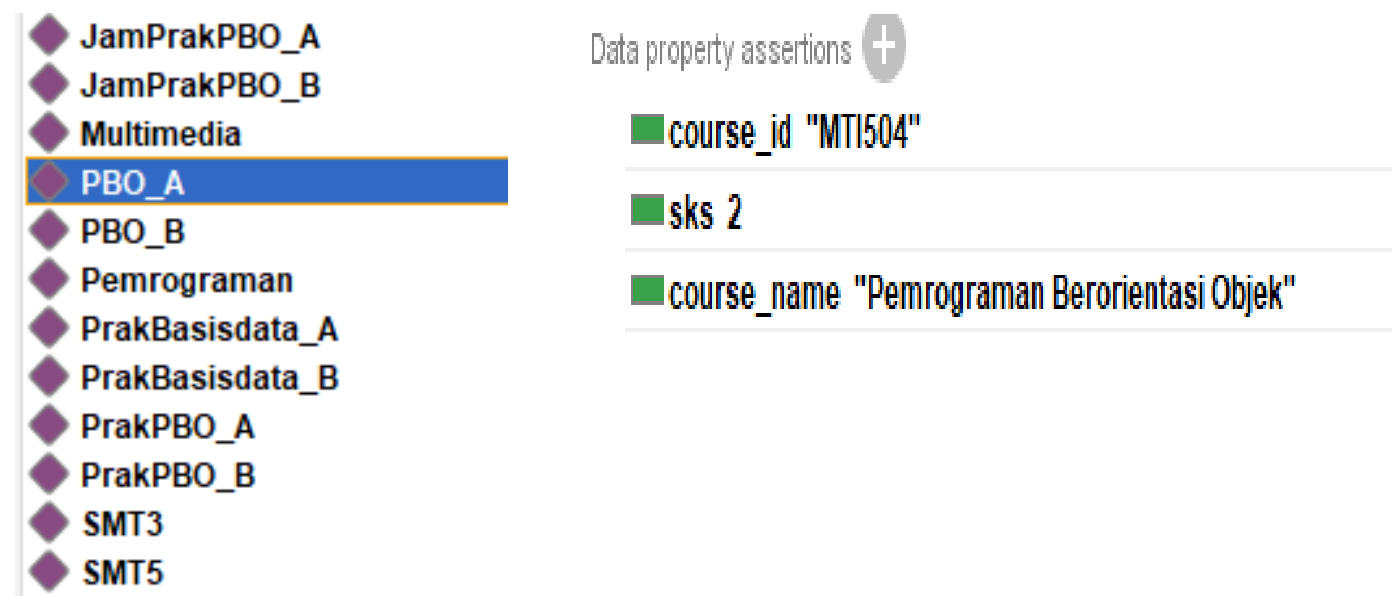

Gambar 3. Instance kelas dan Data property kelas

Setelah dilakukan implementasi ontologi, proses selanjutnya adalah menambahkan individual/ instance. Instance merupakan individu yang diciptakan/dibuat, individu ini bisa instance dari subclass atau superclass. Contoh individu yang telah dibuat adalah individu matakuliah $\mathrm{PBO}$ A, dimana individu tersebut memiliki data property course_name: Pemrograman Berorientasi Objek. Selain itu, individu PBO_A juga memiliki object property yang menghubungkan kepada objek-objek yang lain seperti teachBy (Dosen), hasYear (Tahun_Akademik), hasClss (Kelas), hasPeriod (Periode), hasRoom (Ruangan), hasTime (Waktu), hasSemester (Semester). Gambar 4 menyajikan beberapa objek property yang digunakan untuk setup matakuliah.

\subsection{Pengujian Ontologi}

Pengujian ontologi diperlukan untuk melihat konsep ontologi yang telah dibangun apakah sesuai dengan kebutuhan sistem penjadwalan. Pada pengujian ini terdapat beberapa aspek yang akan digunakan untuk melihat hasil dari penerapan konsep ontologi, yaitu. Aspek-aspek tersebut, diantaranya:

1) Aspek perancangan, aspek ini digunakan untuk menguji sejauh mana penerapan konsep ontologi diterapkan, pengujian implementasi ini dilakukan dengan melihat penerapan hasil perancangan ontologi menggunakan Protege.

2) Aspek pencarian instance pada sistem penjadwalan, aspek ini dilakukan dengan memberikan pertanyaan- pertanyaan untuk menguji ontologi, daftar pertanyaan pada tabel 3 digunakan sebagai dasar untuk menampilkan informasi yang dibutuhkan, pertanyaan- pertanyaan tersebut diuji dengan menggunakan queri SPARQL.

\subsection{Pengujian Ontologi dengan Query $S P A R Q L$}

Setelah dilakukan implementasi ontologi dan penambahan individu/ instant pada setiap class, tahapan selanjutnya sebelum ontologi dapat digunakan dalam pengembangan semantik web, perlu dilakukan pengujian terhadap pengetahuan ontologi yang telah dibuat. Pengujian ini dilakukan dengan memberikan beberapa pertanyaan yang berbasis pada pengetahuan. Pada tabel 3 merupakan daftar pertanyaan berbasis pengetahuan yang akan digunakan untuk menguji ontologi sistem penjadwalan kuliah. 
Tabel 3. Pertanyaan pengujian ontologi penjadwalan kuliah

\begin{tabular}{cl}
\hline No & \multicolumn{1}{c}{ Pertanyaan } \\
\hline 1 & $\begin{array}{l}\text { Tampilkan Daftar matakuliah dan sks yang di ampu oleh } \\
\text { dosen bernama Ahmad Jazuli, M.Kom? }\end{array}$ \\
2 & $\begin{array}{l}\text { Jadwal Kuliah dosen bernama Ahmad Jazuli, M.Kom } \\
\text { untuk Matakuliah Praktikum Pemrograman Basisdata. }\end{array}$ \\
3 & $\begin{array}{l}\text { Daftar matakuliah diampu oleh dosen bernama } \\
\text { Mukhamad Nurkamid, S.Kom, M.Cs di Laboratorium } \\
\text { Pemrograman } \\
\text { Menampilkan semua matakuliah Praktikum di Semester } \\
\text { Gasal 2020/2021 }\end{array}$ \\
\hline
\end{tabular}

Berdasarkan pertanyaan-pertanyaan pada tabel 3, maka dilakukan pengujian ontologi penjadwalan, pengujian ini dilakukan dengan menggunakan queri SPARQL dengan memasukan beberapa kriteria. Gambar 4 adalah memperlihatkan hasil dari pencarian matakuliah dan sks yang diampu oleh dosen bernama Ahmad Jazuli, M.Kom.

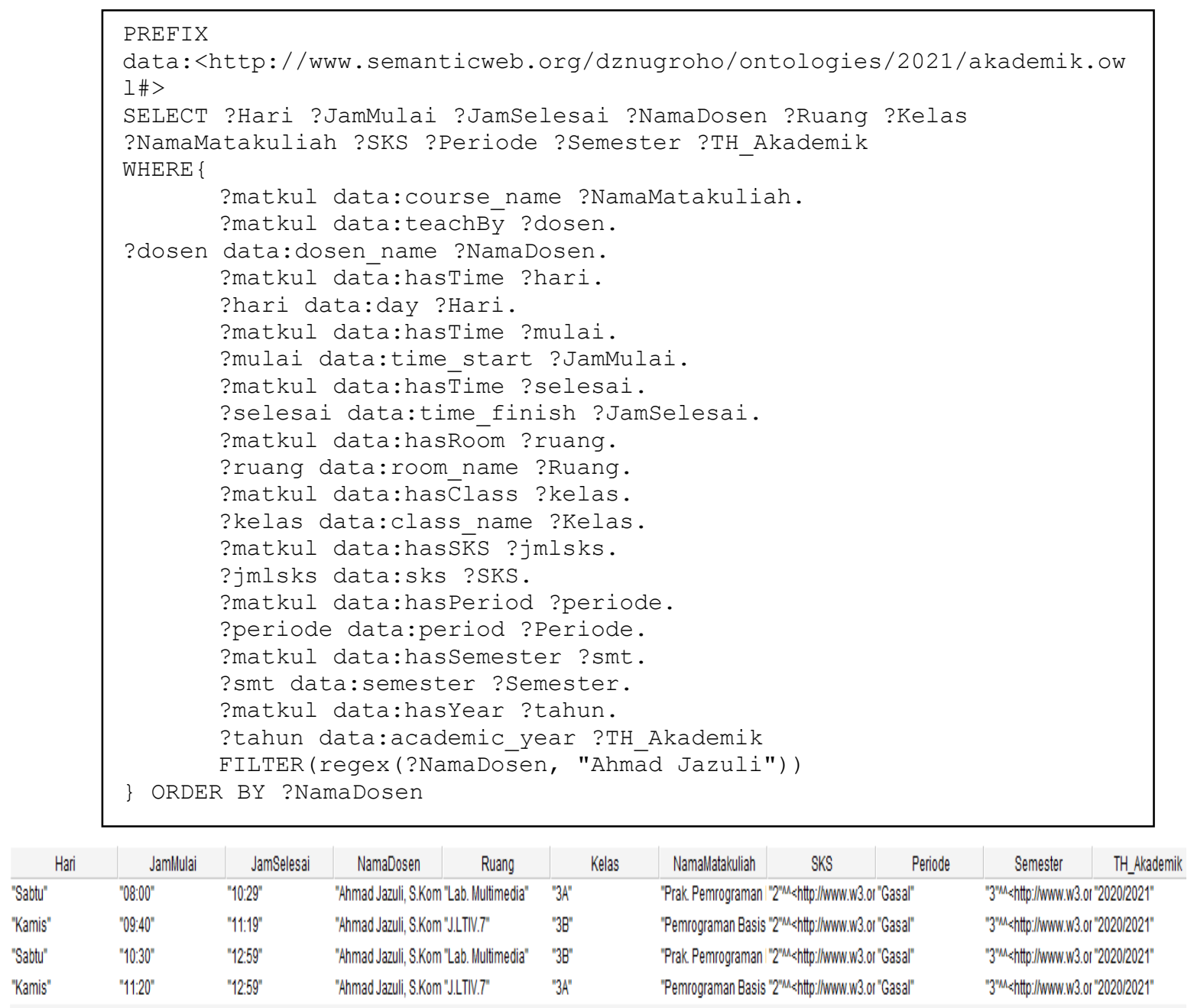

Gambar 4. Query SPARQL untuk menampilkan matakuliah dan SKS.

Gambar 5 adalah memperlihatkan hasil dari pencarian matakuliah Praktikum Pemrograman Basisdata yang diampu oleh dosen bernama Ahmad Jazuli, M.Kom. 


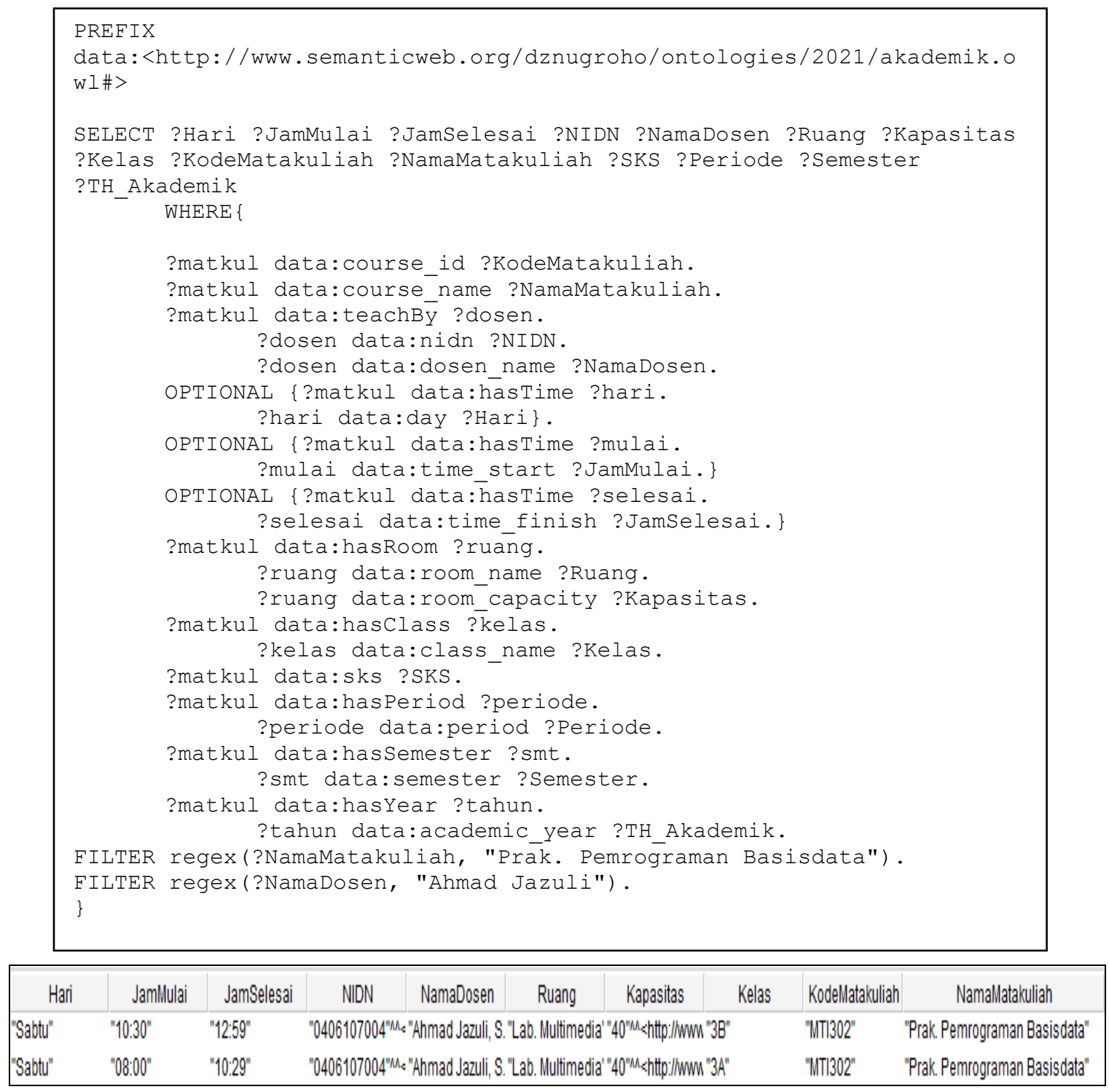

Gambar 5. Query SPARQL untuk menampilkan matakuliah Prak.Pemrograman

Basisdata dengan dosen Ahmad Jazuli.

\subsection{Pengujian Ontologi melalui Aplikasi}

Pengujian ontologi melalui aplikasi ini dikembangkan dengan Bahasa pemrograman PHP dan framework RAP (RDF API for PHP) sebagai media untuk menghubungkan ontologi ke bahasa pemrograman PHP. Pada gambar 6 dapat diperlihatkan contoh pengujian melalui aplikasi dengan melakukan pencarian jadwal sederhana untuk matakuliah "Rekayasa Perangkat Lunak".

\section{Pencarian Jadwal Kuliah \\ Nama Matakuliah $\vee$ Rekayasa Perangkat Lunak Cari}

Gambar 6. Pengujian Ontologi dengan Aplikasi 
Hasil proses pencarian dari matakuliah "Rekayasa Perangkat Lunak" dapat ditampilkan melalui web browser yang didalamnya memuat deskripsi jadwal seperti Matakuliah, Nama Dosen, Ruang, SKS dan Hari Jadwal tersebut dilaksanakan (Gambar 7).

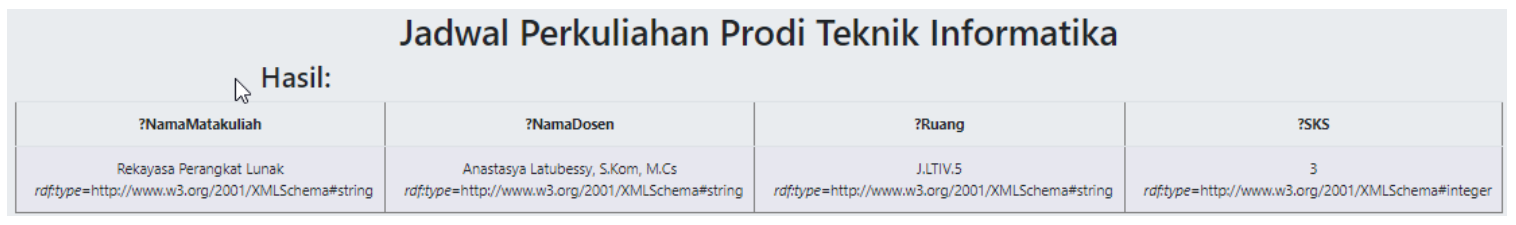

Gambar 7. Hasil Pengujian Ontologi dengan Aplikasi

\section{Kesimpulan}

Dalam penelitian ini dapat diberikan kesimpulan sebagai berikut:

a. Telah berhasil dibangun model penjadwalan berbasis teknologi semantik web memanfaatkan ontologi sebagai representasi informasi berbasis pengetahuan.

b. Pengetahuan tentang informasi jadwal kuliah dapat disimpan dalam class-class seperti class CivitasAkademika dengan subclass Dosen dan class Jadwal dengan subclass Kelas, Matakuliah, Ruangan, Semester, SKS, dan Waktu dan class Periode dan Tahun_Akademik.

c. Ontologi yang dibangun mampu merepresentasikan jadwal kuliah pada Program Studi Teknik Informatika seperti menampilkan data hari, jam mulai, jam selesai, nama dosen, ruang, kelas, nama matakuliah, sks, periode, semester dan tahun akademik.

\section{References}

[1] A. Nugroho, "Penyimpanan Informasi Dengan Rdf," J. Transform., vol. 10, no. 2, p. 47, Jan. 2013, doi: 10.26623/transformatika.v10i2.70.

[2] J. Simarmata, Rekayasa Web. Yogyakarta: Penerbit Andi, 2010.

[3] J. Davies, R. Studer, and P. Warren, Semantic Web Technologies: Trends and Research in Ontology-based Systems. John Wiley and Sons, 2006.

[4] N. F. Noy and D. L. Mcguinness, "Ontology Development 101: A Guide to Creating Your First Ontology,” 2001. Accessed: Jan. 07, 2021. [Online]. Available:

http://www.ksl.stanford.edu/people/dlm/papers/ontology-tutorial-noy-mcguinnessabstract.html.

[5] N. Y. S. Prasetyo Imam Nugroho, Bayu Priyambadha, "Sistem Pencarian Koleksi Laporan Skripsi Dan PKL dengan Teknologi Web Semantik (Studi Kasus: Ruang Baca Fakultas Ilmu Komputer Universitas Brawijaya)," Jurnal Pengembangan Teknologi Informasi dan Ilmu Komputer, Vol. 2 No.9, 2018. http://j-ptiik.ub.ac.id/index.php/jptiik/article/view/2313/856 (accessed Jan. 07, 2021).

[6] M. Nurkamid, "Aplikasi Bibliografi Perpustakaan berbasis Teknologi Web Sematik," Tesis S2 Ilmu Komputer, FMIPA, Universitas Gadjah Mada, 2009. http://etd.repository.ugm.ac.id/home/detail_pencarian/42339 (accessed Jan. 08, 2021).

[7] F. A. B. Prasetya, Eka Devi, Bayu Priyambadha, "Sistem Aplikasi Pencarian Dosen Pembimbing Skripsi dengan Teknologi Web Semantik (Studi Kasus: Fakultas Ilmu Komputer Universitas Brawijaya)," Jurnal Pengembangan Teknologi Informasi dan Ilmu Komputer, Vol.3, No.9, 2019. http://j-ptiik.ub.ac.id/index.php/jptiik/article/view/6333/3044 (accessed Jan. 07, 2021). 
[8] A. Elviwani, "Implementasi Resource Description Framework Dalam Semantic Web Berbasis Ontologi Pada Sistem Pencarian Informasi Obat," 2018. [Online]. Available: http://repositori.usu.ac.id/handle/123456789/5533.

[9] K. D. P. Novianti and R. A. N. Diaz, "Sistem Pencarian Program Studi Pada Perguruan Tinggi di Bali Berbasis Semantik," JST (Jurnal Sains dan Teknol. Univ. Pendidik. Ganesha, vol. 6, no. 1, Mar. 2017, doi: 10.23887/jst-undiksha.v6i1.9111.

[10] A. S. Lasmedi Afuan, "Model Ontologi untuk Informasi Pariwisata di Kabupaten Banyumas," SEMNASTEKNOMEDIA ONLINE, vol. 4, no. 1, pp. 6-7, Feb. 2016, Accessed: Jan. $07, \quad 2021 . \quad$ [Online]. Available: https://ojs.amikom.ac.id/index.php/semnasteknomedia/article/view/1348.

[11] B. Yu, "Research On Information Retrieval Model Based On Ontology," EURASIP J. Wirel. Commun. Netw., vol. 2019, no. 1, p. 30, Dec. 2019, doi: 10.1186/s13638-019-1354$\mathrm{z}$. 